\title{
Severe vivax malaria in Eastern India
}

\author{
Joydeep Mukherjee ${ }^{1}$, Pradeep Chakrabarty ${ }^{2}$
}

${ }^{1}$ RMO Cum Clinical Tutor, Department of Neuro-Medicine, Nilratan Sircar Medical College, Kolkata, ${ }^{2}$ Associate Professor, Department of Medicine, Vivekananda Institute of Medical Sciences, Kolkata

Background: Conventionally, vivax malaria was called as benign malaria. But recent reports of severe vivax malaria were coming from different parts of the World. We studied to find out different attributes of patients, suffering from Plasmodium vivax to reveal some key pattern of severe vivax malaria. Methods: Retrospective, observational and cross-sectional study was conducted comprising first hundred malaria indoor cases in a tertiary hospital in Kolkata, India, having unstable transmission. Their various parameters were noted in MS-Excel software. Malaria species was identified and severe malaria cases were noted according to WHO criteria. Data was analysed with GraphPad Instat Software. Results: Among 57 vivax malaria cases, $16(28.1 \%)$ were having severe malaria and among 32 falciparum malaria cases, $11(34.4 \%)$ were having severe malaria; without significant difference between two species in incidence of severe malaria manifestations. Two (18.2\%) patients suffering from mixed malaria had severe malaria. Jaundice was the commonest severe malaria manifestation. Conclusion: Incidence of severe vivax malaria was high. Severe malaria manifestations were present in vivax and falciparum cases, without significant difference.

Key words: Severe, Malaria, Vivax, Falciparum

\section{INTRODUCTION}

Malaria had posed serious public health problem in India as well as a large part of world, particularly Plasmodium falciparum, which was prone to develop complications including death. Plasmodium vivax (benign tertian malaria) was known to produce relatively uncomplicated disease with rarely causing death. Contrary to popular belief, in recent years, there had been several case reports of falciparumlike syndrome attributed to Plasmodium vivax. Whether Plasmodium vivax was changing its attributes or it was the host response towards Plasmodium vivax, that was changing, was not known. Peter W. Gething et al ${ }^{1}$ had reported that 43.9 million square kilometre area and 2,488.37 million people were at risk of Plasmodium vivax malaria all over the world.

\section{MATERIALS AND METHODS}

The study was conducted in a tertiary medical teaching institute in Eastern India from August 2009 to July 2011. We had included first hundred indoor cases where malaria was detected using microscopy and/or rapid antigen method without using any sampling technique. Cases were collected from various districts of Eastern India, including both genders of different age group from both urban and rural areas, who got admitted in Medicine ward of this hospital. OPD cases were excluded.

The study was retrospective, observational and crosssectional. Malaria detection was done with microscopy and/ or rapid antigen detection methods. The diagnosis of malaria with microscopy rested on demonstration of asexual forms of parasite in stained thick and thin peripheral blood smear using Giemsa stain at $\mathrm{pH}$ 7.2. Rapid antigen test was done using SD BIOLINE Malaria Antigen P.f./P.v. test kit, which was one step, rapid, qualitative and differential test for the detection of Histidine-rich protein II specific to Plasmodium falciparum and Plasmodium lactate dehydrogenase specific to Plasmodium vivax in human blood sample. Severe malaria cases were identified according to $\mathrm{WHO}$ criteria. $^{2}$

Every patient's demographic information and hospital serial number were recorded from hospital record sheet. Patient's history and examination findings were noted 
from the history sheet. Each patient had undergone following investigations, namely complete hemogram, peripheral blood smear examination, blood sugar, liver and renal function test, urine routine examination and microscopy.

The data were entered on to an Ms-Excel spreadsheet; the mean value and standard deviation were measured. Unpaired t test was used for parametric comparisons and proportions were examined using two-sided Fisher's exact test; using GraphPad Instat software. p $<0.05$ was taken as the cut-off for significance.

\section{RESULTS}

Among hundred malaria patients, fifty- seven cases were infected with vivax malaria, thirty-two cases were infected with falciparum malaria and rest were suffering from mixed malaria. Among fifty-seven cases with vivax malaria, sixteen cases $(28.1 \%)$ were detected to have suffering from severe or complicated malaria according to WHO guidelines. ${ }^{2}$ Similarly eleven $(34.4 \%)$ out of thirty-two cases suffering from falciparum malaria and two $(18.2 \%)$ out of eleven cases suffering from mixed malaria were detected to have severe disease.

Seventy five percent of patients suffering from severe vivax malaria were male, whereas in cases of falciparum malaria, it was $45.5 \%$ and in cases of mixed malaria, it was $50 \%$; the difference being non-significant. The mean age \pm standard deviation were $37 \pm 21$ years in cases suffering from severe vivax malaria, $31 \pm 18$ years in cases suffering from severe falciparum malaria and $47 \pm 9$ years in cases suffering from severe mixed malaria; the difference being not significant.

Patients, who were suffering from severe vivax malaria, had presented with a variety of severe manifestations as described in WHO guidelines. ${ }^{2}$ Jaundice with other vital organ dysfunction was the commonest severe manifestation $(12.3 \%$ of total 57 vivax malaria cases); followed by arousable impaired consciousness $(8.8 \%)$, respiratory distress (non-ARDS) (5.3\%), hypoglycaemia $(5.3 \%)$, acute respiratory distress syndrome (ARDS) $(3.5 \%)$, acute renal failure $(1.8 \%)$, un-arousable coma $(1.8 \%)$ and convulsion $(1.8 \%)$, in the order of incidence.

In patients suffering from falciparum malaria, severe malaria had been detected in eleven patients with presence of variety of severe manifestations. Jaundice with other vital organ dysfunction was the commonest severe manifestation in falciparum cases also $(15.6 \%$ of total 32 falciparum malaria cases); followed by arousable impaired consciousness $(12.5 \%)$, respiratory distress (non-ARDS) $(6.3 \%)$, acute renal failure $(6.3 \%)$, acute respiratory distress syndrome (ARDS) (3.1\%), un-arousable coma (3.1\%) and convulsion $(3.1 \%)$, in the order of incidence.

Two patients suffering from mixed malaria had severe disease. One $(9.1 \%)$ of them had acute renal failure and the other patient $(9.1 \%)$ was suffering from arousable impaired consciousness.

Severe manifestation-wise comparison of different severe malaria patients was shown in figure 1 and comparison regarding organ-system failure was shown in figure 2 .

We had not found significant difference of hemoglobin level between patients suffering from benign and severe vivax malaria $(12.2 \pm 1.6 \mathrm{gm} / \mathrm{dl}$ vs. $11.6 \pm 2.6 \mathrm{gm} / \mathrm{dl}$, $\mathrm{p}=0.39)$ but we had found mean platelet count to be significantly lower (24221 per micro litre) in patients

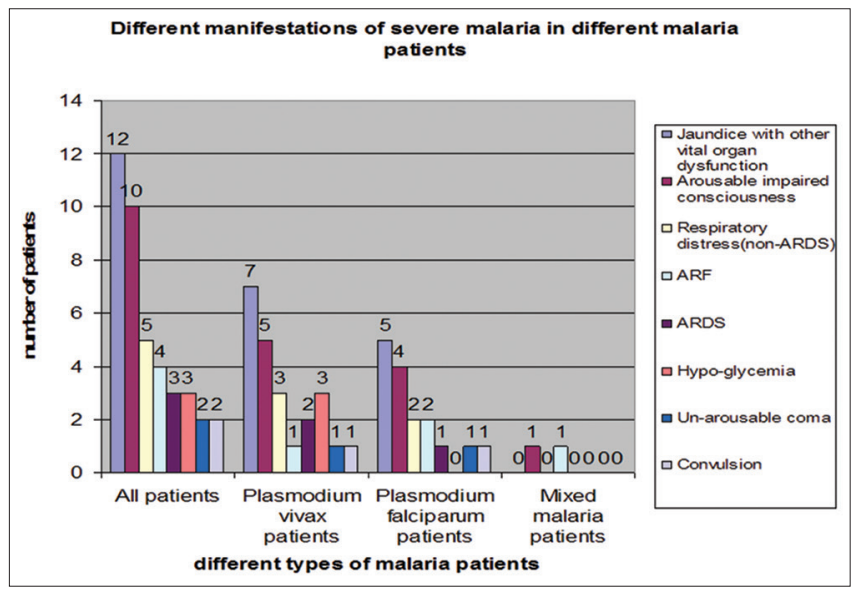

Figure 1: Different types of malaria patients having different severe malaria manifestations

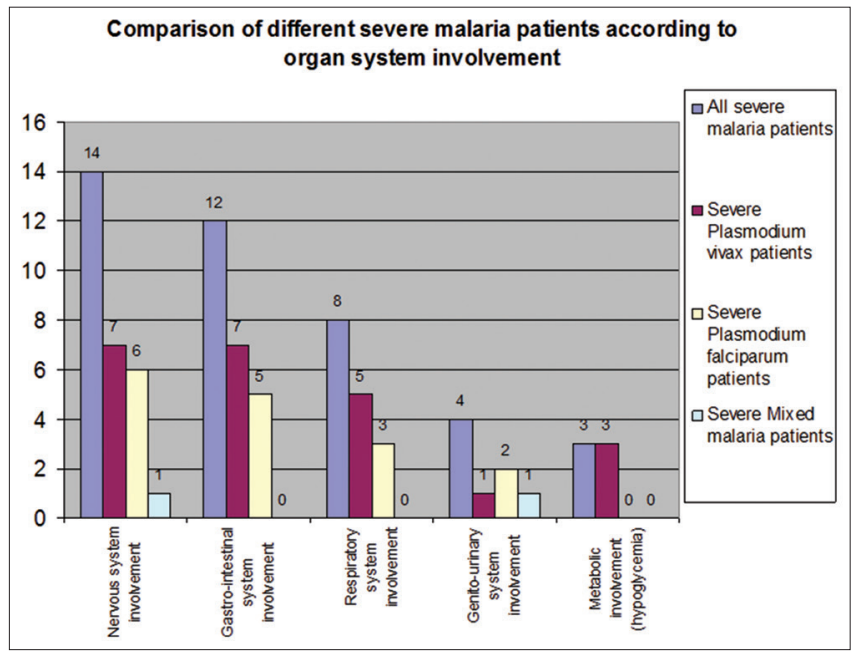

Figure 2: Comparison of different malaria patients according to different organ system failure 
suffering from severe vivax malaria, in comparison to patients suffering from benign vivax malaria (65438 \pm 31602 vs. $89659 \pm 35203, \mathrm{p}=0.01)$.

In our study, blood smear of only 29 out of 41 patients suffering from benign vivax malaria, were found positive for malaria parasite; whereas, blood smear of all of the 16 patients suffering from severe vivax malaria were found positive for malaria parasite; the difference being very significant $(p=0.01)$. But rapid antigen test was positive in most of the patients of the two groups of vivax malaria, the difference being insignificant (40 out of 41 vs. 16 out of $16, \mathrm{p}=1)$.

ICU treatment was needed for three patients and mechanical ventilation was needed for one patient with severe vivax malaria but no such adverse situation had happened for patients with benign vivax malaria.

There were similar periods of persistence of symptoms during treatment for cases with both categories of vivax malaria ( $2 \pm 1$ days vs. $2 \pm 1$ days, $\mathrm{p}>0.99$ ); also the duration of hospital stay was not significantly different ( $4 \pm 2$ days vs. $5 \pm 3$ days, $p=0.23$ ). The cost of treatment, which was comprised of bed charge, investigation charge and cost of medicines, was higher by Indian Rupees 3206 in cases suffering from severe vivax malaria in comparison to cases suffering from benign vivax malaria (Indian Rupees $6338 \pm 4978$ vs. Indian Rupees $3132 \pm$ 1591, $\mathrm{p}=0.02)$.

Table 1 had shown comparison between cases suffering from Plasmodium vivax malaria and cases suffering from Plasmodium falciparum malaria regarding severe malaria features. It was evident from Table 1 that there was no statistically significant difference between patients suffering from vivax and falciparum malaria regarding incidence of severe malaria manifestations.

\section{DISCUSSION}

Incidence of severe vivax malaria was high throughout the world. A comparison of our study with previous similar studies was shown in Table 2.

In our study, $28.1 \%$ of patients suffering from vivax malaria were having severe malaria; whereas, Kochar DK et al ${ }^{6}$ found it to be $8.77 \%$, Tjitra $\mathrm{E}$ et $\mathrm{al}^{4}$ found it to be $23 \%$ and Andrade BB et al ${ }^{7}$ found it to be $14.72 \%$.

The average age of our cases was in fourth decade of life which was a bit higher than the cases of studies mentioned above.

\begin{tabular}{|c|c|c|c|}
\hline & $\begin{array}{c}\text { Plasmodium } \\
\text { vivax malaria } \\
\quad(n=57)\end{array}$ & $\begin{array}{l}\text { Plasmodium } \\
\text { falciparum } \\
\text { malaria }(n=32)\end{array}$ & $P$ value \\
\hline \multicolumn{4}{|l|}{ Severe malaria features } \\
\hline $\begin{array}{l}\text { Jaundice with other } \\
\text { vital organ dysfunction }\end{array}$ & $7(12.3)$ & $5(15.6)$ & 0.75 \\
\hline $\begin{array}{l}\text { Arousable impaired } \\
\text { consciousness }\end{array}$ & $5(8.8)$ & $4(12.5)$ & 0.72 \\
\hline $\begin{array}{l}\text { Respiratory distress } \\
\text { (non-ARDS) }\end{array}$ & $3(5.3)$ & $2(6.3)$ & 1.00 \\
\hline ARF & $1(1.8)$ & $2(6.3)$ & 0.29 \\
\hline ARDS & $2(3.5)$ & $1(3.1)$ & 1.00 \\
\hline Hypo-glycemia & $3(5.3)$ & $0(0)$ & 0.55 \\
\hline Un-arousable coma & $1(1.8)$ & $1(3.1)$ & 1.00 \\
\hline Convulsion & $1(1.8)$ & $1(3.1)$ & 1.00 \\
\hline $\begin{array}{l}\text { Total severe malaria } \\
\text { cases }\end{array}$ & $16(28.1)$ & $11(34.4)$ & 0.63 \\
\hline
\end{tabular}

\begin{tabular}{|c|c|}
\hline Findings in our study & $\begin{array}{l}\text { Previous studies } \\
\text { having similar results }\end{array}$ \\
\hline $\begin{array}{l}\text { Falciparum like severe } \\
\text { malaria in vivax }\end{array}$ & 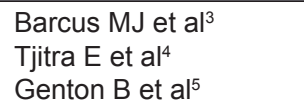 \\
\hline $\begin{array}{l}\text { Liver dysfunction as most } \\
\text { common severe malaria } \\
\text { feature }\end{array}$ & 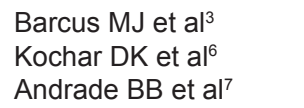 \\
\hline $\begin{array}{l}\text { Significant } \\
\text { thrombocytopenia in vivax }\end{array}$ & Erhart LM et $\left.a\right|^{8}$ \\
\hline $\begin{array}{l}\text { Male commoner in severe } \\
\text { vivax malaria }\end{array}$ & Kocher DK et al ${ }^{6}$ \\
\hline $\begin{array}{l}\text { Cerebral malaria present } \\
\text { in severe vivax malaria }\end{array}$ & 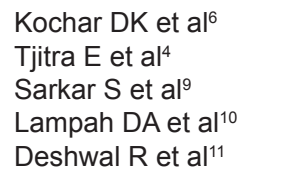 \\
\hline $\begin{array}{l}\text { Hypoglycemia present in } \\
\text { severe vivax malaria }\end{array}$ & Kochar DK et al ${ }^{6}$ \\
\hline
\end{tabular}

In our study, cases had male preponderance. The reason behind it was not known, but it can be postulated that higher outdoor habit, higher incidence of work in the evening and night and less body-covering garments by Indian males than their female counterparts might be the cause.

In comparison of cases suffering from severe vivax and falciparum malaria (table 1), it was found that there was no significant difference of incidence of severe malaria manifestations between two categories. However, no patients suffering from severe vivax malaria had died but two $(18.2 \%)$ patients suffering from severe falciparum malaria had died; like the study done by Lampah DA et al ${ }^{10}$ in Papua, Indonesia. 
Our patients suffering from severe vivax malaria had significantly higher body temperature than patients suffering from benign vivax malaria. Whether that variation was due to increased levels of pyrogenic cytokines in patients suffering from severe vivax malaria, was not known. Karunaweera ND et al ${ }^{12}$ from Colombo, Sri Lanka, in a review article, had discussed host-parasite interaction during paroxysms of vivax malaria.

Platelet count was significantly lower in patients suffering from severe vivax malaria than their benign counterparts. Whether thrombocytopenia would be incorporated as a determining manifestation of severe malaria, would be a matter of future research.

Bharti PK et al ${ }^{13}$ had shown that rapid antigen testing for malaria was highly efficacious in comparison to microscopy. We had found similar result. Moreover, we had found that all severe vivax malaria cases were microscopy positive, whereas, benign vivax malaria cases were mostly microscopy negative. We could postulate high parasitemia to be the reason behind severe vivax manifestations.

To conclude, the incidence of severe vivax malaria was found to be high. There was no significant difference between patients suffering from Plasmodium vivax and Plasmodium falciparum malaria regarding presence of severe malaria manifestations. Severe vivax malaria cases were significantly higher microscopy positive than their benign counterparts; whereas rapid antigen test was mostly positive for both categories. Mortality from severe vivax malaria was less than severe falciparum malaria. Jaundice was the commonest severe manifestation in severe vivax and falciparum malaria followed by impaired consciousness. Thrombocytopenia might be included as a severe manifestation in future.

\section{Synopsis}

Severe malaria features were not significantly different between patients suffering from vivax and falciparum malaria.

\section{REFERENCES}

1. Gething PW, Elyazar IR, Moyes CL, Smith DL, Battle KE, Guerra CA, et al. A long neglected World malaria map: Plasmodium vivax endemicity in 2010. PLoS Negl Trop Dis 2012; 6(9): e1814.

2. World Health Organization. Guidelines for the treatment of Malaria, Second edition (ISBN 978924154792 5). 2010; page 35 .

3. Barcus MJ, Basri H, Picarima H, Manyakori C, Sekartuti, Elyazar I, et al. Demographic risk factors for severe and fatal vivax and falciparum malaria among hospital admissions in north-eastern Indonesian Papua. Am J Trop Med Hyg 2007; 77: 984-991.

4. Tjitra E, Anstey NM, Sugiarto P, Warikar N, Kenangalem E, Karyana $M$, et al. Multidrug-resistant Plasmodium vivax associated with severe and fatal malaria. A prospective study in Papua, Indonesia. PLoS Med 2008; 5: e128 (doi: 10.1371/ journal.pmed.0050128).

5. Genton B, D'Acremont V, Rare L, Baea K, Reeder JC, Alpers MP, et al. Plasmodium vivax and mixed infections are associated with severe malaria in children: a prospective cohort study from Papua New Guinea. PLoS Med 2008; 5: e127.

6. Kochar DK, Das A, Kochar SK, Saxena V, Sirohi P, Garg S, et al. Severe Plasmodium vivax malaria: A Report on Serial Cases from Bikaner in North-western India. Am J Trop Med Hyg 2009; 80(2): 194-198.

7. Andrade BB, Reis-Filho A, Souza-Neto SM, Clarencio J, Camargo LMA, Barral A, et al. Severe Plasmodium vivax malaria exhibits marked inflammatory imbalance. Malaria Journal 2010; 9: 13.

8. Erhart LM, Yingyuen K, Chuanak N, Buathong N, Laoboonchai A, Miller RS, et al. Hematologic and Clinical Indices of Malaria in a Semi-Immune Population of Western Thailand. Am J Trop Med Hyg 2004; 70(1): 8-14.

9. Sarkar $S$ and Bhattacharya P. Cerebral malaria caused by Plasmodium vivax in adult subjects. Indian Journal of Critical Care Medicine 2008; 12 (4): 204-205. (doi: 10.4103/09725229.45084).

10. Lampah DA, Yeo TW, Hardianto SO, Tjitra E, Kenangalem E, Sugiarto $P$, et al. Coma Associated with Microscopy-Diagnosed Plasmodium vivax: A Prospective Study in Papua, Indonesia. PLoS Negl Trop Dis 2011; 5(6): e1032. (doi: 10.1371/journal.pntd.0001032).

11. Deshwal R. Vivax Malaria - Not Benign Anymore. Journal, Indian Academy of Clinical Medicine 2011; 12(2):150-152.

12. Karunaweera ND, Wijesekera SK, Wanasekera D, Mendis KN and Carter R. The paroxysm of Plasmodium vivax malaria. Trends in Parasitology 2003; 19 (4): 188-193. (doi: 10.1016/ S1471-4922(03)00036-9).

13. Bhati PK, Silawat N, Singh PP, Singh MP, Shukla M, Chand G, et al. The usefulness of a new rapid diagnostic test, the First Response Malaria Combo (pLDH/HRP2) card test, for malaria diagnosis in the forested belt of central India. Malaria Journal 2008; 7: 126.

\section{Authors Contribution:}

JM - Study design, Collection of Data, Analysis of Data, Review of literature, Writing of manuscript; PC - Intellectual inputs, Review of literature, Peer review of manuscript.

Source of Support: Nil, Conflict of Interest: None declared. 